\title{
MAS EU FUI UMA ESTRELA DO FUTEBOL! AS INCOERÊNCIAS SOCIOLÓGICAS E AS CONTROVÉRSIAS SOCIAIS DE UM MILITANTE SEM-TERRA SUL-AFRICANO*
}

Marcelo C. Rosa

\section{Introdução}

A primeira vez que encontrei Mangaliso Kubheka foi em 2005. Naquela ocasião, ele recebia a visita de dois militantes brasileiros do Movimento dos Trabalhadores Rurais Sem Terra (MST) - acompanhados por mim - na sede do Landless Peoples Movement (LPM) em Johanesburgo, África do Sul, na condição de national organizer do movimento. A partir daí, tive a oportunidade de encontrá-lo e acompanhá-lo em sete períodos distintos entre março de 2006 e janeiro de 2011. Durante todo esse período, Mangaliso foi minha porta de entrada para a pesquisa sobre o movimento que organizava e, ao mesmo tempo, um guia privilegiado para a compreensão da complexa questão da reforma da terra no pós-apartheid. ${ }^{1}$ Por ser um porta-voz, as atividades desempenhadas por ele soavam, para neófitos no país e seus problemas, como típicas ideias de um militante sem-terra sul-africano. Por um longo tempo, procurei associar a ele traços gerais que contribuíssem para a caracterização do movimento, de um tipo social, de uma identidade, entre outros rótulos que comumente usamos para falar de movimentos e militantes. $^{2}$

O problema que este texto coloca, no sentido sociológico da palavra, é o de que, a cada novo encontro, a relação que ele mantinha com o LPM mostrava-se um pouco diferente. Apresentava um precedente nas palavras de Stengers (2002:36). Quanto mais tempo passávamos juntos, mais nos afastávamos do espaço físico da sede do movimento e do tempo dedicado à sua militância como sem-terra. Fora da atmosfera do movimento, passávamos a conversar sobre sua história pessoal, sua família, o local de moradia, sua paixão pelo futebol, sua religião e o que chama de sua cultura. ${ }^{3}$ Encontrá-lo por várias vezes, em situações distintas, permitia ainda interagir com outras pessoas com as quais ele se relacionava e que tinham também observações 
a fazer sobre sua condição de militante sem-terra, de preacher da igreja metodista, de pai, de irmão mais velho e de homem zulu. ${ }^{4}$ Todos à sua volta criavam expectativas sobre sua conduta, mas, como veremos a seguir, era no movimento - meu objeto de investigação inicial — que esses diferentes engajamentos se mostravam, por vezes, incompatíveis ou incompreensíveis. ${ }^{5}$

Em uma dessas ocasiões, quando eu lhe fazia perguntas que tentavam o tempo todo relacionar coerentemente sua vida pessoal ao movimento social, à terra onde vivia e a seus costumes zulus, ele rapidamente me explicou: "você não sabe quem eu fui, mas eu era uma estrela do futebol". E rapidamente me lembrou que ser uma estrela dos gramados - como jogador do Benfica de Tokoza - traz marcas que se podem carregar para o resto da vida, como os diversos filhos que teve com suas fãs. A desconcertante resposta de Mangaliso inspira este texto justamente porque ela desperta uma dúvida fundamental: como tratar sociologicamente os militantes de um movimento social sem reduzi-los ao próprio movimento? E, por conseguinte, como tratar um movimento social sem perder de vista a diversidade social de seus membros e os vários engajamentos que eles possuem para além de nosso objeto de estudo? Nas próximas páginas procurarei explorar o tempo de pesquisa com este militante de modo a demonstrar que quanto mais expandimos o conhecimento sobre esses sujeitos e suas vidas, mais difícil se torna falar de uma biografia militante ou de uma trajetória que conecte diretamente a agência de um indivíduo às estruturas políticas de que participa. Nesse sentido, tratar de um movimento de sem-terra cujo organizador havia sido uma estrela do futebol, sem que isto sirva para exotizar ou deslegitimar suas ações políticas, é um desafio para uma ciência social que procura agregar as diversidades da vida social em seu escopo.

\section{Desafios teóricos: do militante ao actante}

Um dos problemas centrais, senão o mais central, para os estudos sobre militantes é aquele que relaciona práticas competentes do engajamento em movimentos sociais e partidos políticos a certas disposições sociais para tal tarefa (Fillieule 2001; Gaxie 2002; Seidl 2009; Oliveira 2008). Neste tipo de estudo, o fundamental é a busca dos determinantes do sucesso e do insucesso político na ocupação de funções sociais específicas ou na socialização em ambientes propícios. Na linguagem utilizada de forma corrente: aquisição de capital militante. Estas pesquisas tendem a acentuar as características mais recorrentes em entrevistas, questionários e depoimentos quanto a determinantes da chamada carreira militante. O problema sociológico advindo 
dessas análises é que, na grande maioria dos casos, tomam-se apenas os militantes bem-sucedidos e que já ocupam posições privilegiadas. Raramente temos a oportunidade de acompanhar os processos conturbados pelos quais grande parte dos militantes passa. Nesses casos, tendemos a limpar o terreno e mostrar aos nossos leitores aquilo que se convencionou chamar na sociologia de trajetória para militantismo.

Este mesmo dilema já foi apresentado por Pierre Bourdieu em seu clássico "A ilusão biográfica". Naquele texto, somos advertidos seriamente sobre os problemas de se tomar uma história de vida como ela nos é contada por nossos personagens e de aceitarmos como legítimo um sentido artificial imposto pelo biografado (Bourdieu 1996:185). A sugestão deste autor, que também nos adverte sobre o problema de certos agentes que estão em diferentes "campos", é a de construir o "espaço dos possíveis" que determine as posições.

A saída sugerida por Bourdieu nos coloca, porém, diante de outro obstáculo: como determinar o "espaço dos possíveis" quando nosso conhecimento sobre a circulação de nossos personagens é (e sempre será) limitado pelas condições de pesquisa? Apesar de desafiador, este mapeamento de posições, valores, capitais etc. requer dos pesquisadores uma construção que separe o sujeito analisado das chamadas estruturas com as quais convive. Em última instância, ela aceita uma subordinação das agências individuais a regras, dadas a priori, nos espaços sociais a partir do ponto de vista do pesquisador. Saímos da ilusão biográfica para cairmos na ilusão do Deus ex machina do cientista que pode (ou deve) objetivar todas as possibilidades que são dadas por nossos agentes, como se fosse possível antecipar o caminho antes de ele ser cruzado.

Inspirado em outras obras de Bourdieu que salientam a necessidade de se conhecerem os pontos de vista dos envolvidos, Auyero (2004) utiliza as biografias e as experiências de protesto social narradas por duas mulheres ligadas aos piquetes argentinos dos anos 90 para narrar uma das dimensões consideradas ocultas daqueles protestos: o ponto de vista dos militantes. Nas palavras do próprio autor, suas protagonistas são uma espécie de tipo ideal que sintetiza o significado dos protestos por quem os vive. Para isso, o autor busca demonstrar as "continuidades entre suas histórias de vida [...] e suas experiências destes processos de luta" (Auyero 2004:21). Nesta perspectiva, estão em jogo as "disposições subjetivas" que são trazidas à tona durante os protestos. Mesmo com toda a vigilância epistemológica que o autor demonstra ao longo do livro, podemos perceber que o estudo também está centrado nas coerências entre a vida passada (de desrespeito social) e a luta atual por reconhecimento político. 
Em última instância, as três matrizes citadas acima buscam um mesmo tipo de resposta: o que leva um indivíduo a se tornar militante?

Nosso problema, inspirado pelo caso de Mangaliso, orienta-se para outro tipo de questão: como vive socialmente um militante? Nossa proposta, para evitar os dilemas acima, é tomar a sério a noção de associações desenvolvida por Bruno Latour (2005). Nesta perspectiva, a pergunta que deve ser feita é: a que, ao longo de nossas pesquisas, os indivíduos que estudamos se associam para continuar vivendo coletivamente? Quais são os discursos, as posições, os objetos, os sonhos, os indivíduos (e muitas outras coisas) que povoam, no decorrer de nossa pesquisa, a existência coletiva de nossos personagens? Se o caso em questão for de um militante, o movimento, por exemplo, é apenas uma porta de entrada, e ele não pode ser tratado como o princípio unificador de práticas ou mesmo como uma estrutura que já possui uma ordem preexistente. O movimento é uma, entre diversas outras coisas que povoam o mundo dos militantes. Ele deve figurar na forma de uma controvérsia cujo objeto não é o movimento em si, mas a própria existência coletiva de nossos personagens. Como nos adverte Bernard Lahire (2006), é muito difícil que um indivíduo pertença a um só grupo ou figuração: ele está com os movimentos e também com muitas outras coisas. Quanto mais povoadas forem nossas análises, mais complicada será a vida desses sujeitos e mais digna será a fotografia que apresentaremos aos nossos leitores.

Como exercício sociológico será mais importante, para os fins deste texto e deste personagem, descrever as controvérsias da vida de tais indivíduos e os coletivos nos quais existem do que delimitar suas margens de ação pela definição antecipada de universos estruturantes (família, movimento, igreja, cultura). Consideramos que o estabelecimento de margens depende, em termos de método, mais da nossa sorte (de achar uma agulha no palheiro com a qual possamos costurar toda a sua vida social) ou da nossa ignorância (de limitar a vida social de nossos objetos àquilo que nós julgamos de antemão significativo) do que de exercícios racionalizadores exaustivos. Nesse sentido, compreender a militância de Mangaliso não dependerá do conhecimento de sua origem ou de sua trajetória (que, como veremos, é controversa), mas de uma boa descrição do seu presente.

\section{Uma tentadora ficção: o militante ideal}

Os primeiros dias de convívio com Mangaliso, acompanhado de outros ativistas locais e de militantes do MST, contribuíram para a afirmação da ideia de que ele era um militante como outros sem-terra que eu havia encontrado 
no Brasil em pesquisas anteriores (Rosa 2001 e 2009), ou seja, pessoas com dedicação quase total ao movimento e que viam seu engajamento militante como um ponto de transformação, ruptura ou de ápice de seus engajamentos sociais anteriores ${ }^{6}$ Com pouco mais de 50 anos de idade (em 2010 completou 60 anos), sempre vestido com uma camiseta vermelha com a logomarca do movimento e os dizeres "Land, Food and Jobs", ele se comunicava com desenvoltura na maioria das 11 línguas oficiais do país. Nos primeiros 30 dias de nosso contato, ele organizou as visitas dos brasileiros aos principais focos de conflitos por terra no país, conclamando as famílias envolvidas a se unirem ao movimento, participou de programas de TV e negociou recursos com representantes de ONGs. Sempre que estávamos juntos, Mangaliso era "apenas" o líder do LPM.

Esses primeiros momentos com Mangaliso conformaram uma espécie de rotina do tipo de ideal de militante de movimento social. Nos momentos em que estava com ele, as únicas coisas que compartíamos estavam diretamente relacionadas ao LPM. Na casa que servia de sede para o LPM, em um bairro de Johanesburgo, ele e os outros membros do movimento ali presentes cozinhavam, dormiam e atendiam ininterruptamente seus telefones celulares. O envolvimento visceral com a rotina do movimento aproximava-o muito de seus camaradas brasileiros, que reconheciam em Mangaliso um militante como eles próprios. Além de sua conduta diária, sua narrativa pública sobre ser um morador negro de fazenda de brancos (farm dweller), ameaçado de expulsão da terra na qual sua família vivera por várias gerações, ajudava a compor a figura que poderia ser vista também como a do típico sem-terra da África do Sul.

Tipo ideal de militante e de uma categoria social potencialmente mobilizável (os moradores negros de fazendas de brancos que passaram a ser expulsos com o final do apartheid), Mangaliso apresentava uma coerência que deixava qualquer cientista social tranquilo. Sua vida, quando vista de dentro da sede do LPM, podia ser descrita como o resultado de um processo linear de exclusão social e de mobilização diante das injustiças passadas e presentes sofridas pela população negra rural sul-africana.

A associação entre a militância e uma espécie de vitimização dos sujeitos que a praticam é uma chave comum nas ciências sociais, porque permite uma justificação social dos sujeitos estudados e também de nossas pesquisas (Boltanski e Thevenot 1991). Ela é também comum, porque em muitos casos - como foi o meu - chegamos a esse tipo de indivíduo por meio dos movimentos que os tornam figuras públicas e, como nosso tempo de pesquisa é sempre limitado, tendemos a encontrá-los, entrevistá-los e perguntar-lhes sobre suas vidas em situações delimitadas pelos termos cognitivos do movimento. Considerando que pessoas como Mangaliso estão 
nos lugares que estão porque sabem justificar publicamente sua relação com o movimento, tendemos a chegar a um acordo tácito que reduz a história desses sujeitos aos parâmetros de nossas pesquisas: em geral, à vida em movimento. ${ }^{7}$ Ferramentas como o questionário ou mesmo as histórias de vida construídas por meio de entrevistas estanques tornam-se, nesses contextos, armadilhas que capturam a nós mesmos, já que nos encaminhamos para elas em busca de "elementos da realidade" que se encaixem em nossos parâmetros pré-construídos.

A vida em movimento não deixa por isso de ser um objeto legítimo. Ao contrário, ela tende a nos esclarecer sobre aspectos fundamentais do funcionamento e da organização desses grupos que ocupam a cena pública de nossos países, e a entender justamente as faces menos manifestas dessas organizações. No processo de pesquisa com Mangaliso, foi possível compreender que essa vida em movimento - por vezes vista de forma idílica - é o tempo todo tencionada pela pluralidade de situações e de legitimidades que conformam vidas que, para o desespero dos sociólogos, não são necessariamente coerentes. O termo coerente é aqui usado para evitar outros termos como "trajetória". A questão não é procurar os elementos certos na história de Mangaliso que contribuam para explicar seu comportamento de militante, mas sim demonstrar que, mesmo sendo um militante, ela pode conter narrativas, ações e comportamentos diferentes (Lahire 2006). Na próxima seção, procurarei acompanhar e analisar essas situações a partir daquilo que os estudos interessados apenas nos movimentos descrevem como incoerências pessoais que dificultam suas tarefas de liderança.

\section{As incoerências de Mangaliso}

As primeiras incoerências do caso de Mangaliso começaram a ser percebidas por seus colegas brasileiros do MST. Quando chegaram à África do Sul, Vanderlei e Inês militavam, respectivamente, nas sedes do movimento nos estados de Minas Gerais e Maranhão e, assim como eu em minhas pesquisas, tinham a militância no MST como o parâmetro para avaliar seus camaradas sul-africanos.

Mangaliso era o responsável por acompanhar a visita deles e, ao longo dos três meses que passaram na África do Sul encontraram-se praticamente todos os dias. Essa convivência intensa levava-os a ver, a ouvir e a compartilhar situações diversas que envolviam a vida de Mangaliso e do LPM.

Não demorou muito para que ambos percebessem as diferenças na estrutura do movimento e também na forma de militância de Mangaliso. 
Conforme os dias foram passando, os militantes começaram a ver que Mangaliso usava o que consideravam uma parte significativa de seu tempo em movimento para resolver problemas pessoais.

As constantes viagens de carro, cedido por uma ONG, que eles fizeram entre Johanesburgo (localizada no centro do país) e Durban (localizada na província de Kwazulu-Natal no litoral do Índico), foram um exemplo concreto dessas tensões. Apesar de a sede nacional do movimento ficar em Johanesburgo, Mangaliso era oriundo e também representante do LPM de Kwazulu-Natal. Tendo sua base naquela província, ele frequentemente era convocado para encontros locais e regionais para os quais sempre levava os militantes brasileiros.

O caminho entre as duas cidades quase nunca era feito sem uma parada inesperada na casa de Mangaliso, em Ingogo, ou em Pietermaritzburg, na sede da AFRA, a ONG que apoiava o movimento naquela província e que cedia o automóvel para a visita do MST. As passagens pela casa da liderança do LPM implicavam sempre um pernoite não planejado. Essas ocasiões serviam, em geral, para que ele comprasse comida na cidade e levasse para seus filhos que viviam em uma pequena área dentro de uma fazenda na zona rural. Mesmo sendo nobre a causa do desvio, o uso do tempo que deveria ser dedicado ao movimento para um assunto pessoal sempre incomodava.

A mistura entre a agenda do movimento e a agenda pessoal dessa liderança revelava-se um incômodo também quando o destino era a sede da ONG. Para os brasileiros, Mangaliso perdia tempo demais em encontros privados com funcionários daquela organização que, por vezes, parecia ser mais importante para ele que o próprio movimento. Para os brasileiros, a ONG é que deveria ir ao movimento e não o contrário.

No tipo ideal de militância que os militantes brasileiros e eu mesmo como pesquisador tínhamos em mente, o lugar das relações familiares ou com as ONGs (financiadores) era secundário quando comparado ao movimento. ${ }^{8}$ A centralidade do LPM para a visita dos militantes do MST e para a minha pesquisa impunha-se de tal forma sobre a figura de Mangaliso que às vezes não hesitávamos em repreender seu comportamento incoerente diante do fato de ser ele a principal figura de liderança daquela organização.

Como adverti na introdução, o período com Inês e Vanderlei foi minha porta de entrada para o LPM e para a vida de Mangaliso. Depois disso, voltei a passar longos períodos, entre 2006 e 2011, com ele sem a presença de outros militantes brasileiros.

Mesmo sem a companhia daqueles conterrâneos, vi essa liderança receber o mesmo tipo de crítica sobre seus comportamentos que destoavam de sua posição de líder de um movimento social. Desta feita, já não eram 
mais militantes de outros movimentos, mas acadêmicos e funcionários de ONGs que, após os anos de auge do LPM, identificavam os problemas contemporâneos do movimento com as inconsistências no comportamento de Mangaliso.

Para esses críticos, Mangaliso não se comportava como um verdadeiro líder de um movimento social. Ele monopolizava a utilização dos parcos recursos do movimento e não prestava contas de seus gastos e ações de modo apropriado. Além disso, ele também se envolvia em conflitos com outras lideranças do movimento e mantinha uma relação estreita demais com certos órgãos do governo voltados para o tema da reforma agrária, misturando esferas que deveriam supostamente estar apartadas - movimentos sociais e Estado. ${ }^{9}$ Utilizando uma palavra comum a alguns grupos de analistas políticos e funcionários de ONGs, ele não tinha o accountability que se espera de uma liderança popular.

Do lado dos acadêmicos locais, pesquisadores do tema, a crítica a Mangaliso vinha do fato de ele ser dependente demais de certas ONGs que ajudaram a criar o LPM - tendo como pano de fundo a ideia de que o movimento e seus militantes deveriam ser independentes, isto é, uma expressão pura dos genuínos interesses dos sem-terra. ${ }^{10}$

Em suma, o que unia os militantes brasileiros, os funcionários de ONGs, os acadêmicos e eu era o fato de que Mangaliso não se encaixava em nossos modelos de liderança de movimentos sociais. Em razão de nossos enquadramentos teóricos ou em função do exemplo de outros casos como o do MST, suas ações não justificavam de forma coerente o seu papel social. Dentro dos limites deste texto é importante notar que o contato que todos mantínhamos com Mangaliso reduzia-se ao espaço e aos momentos em que ele atuava naquilo que pensávamos ser seu palco principal ou mesmo seu único palco: o LPM.

\section{Mangaliso e sua vida de sem-terra}

Membro fundador do LPM, Mangaliso, sempre que solicitado, apresenta suas credenciais para estar no movimento: ele é um farm-dweller, ou seja, uma pessoa que tem a posse (mas não a propriedade) de uma terra que está localizada em uma fazenda. ${ }^{11}$

Essa situação é comum na África do Sul contemporânea e se origina do fato de que, durante o governo do apartheid, os fazendeiros brancos contavam com mão de obra negra em troca do oferecimento de um pedaço de terra onde essas famílias pudessem manter seu gado e suas casas de barro 
(em muitos casos, sem qualquer remuneração em dinheiro). Essa prática estendeu-se por várias gerações de trabalhadores e de fazendeiros. A terra em que hoje habita Mangaliso, por exemplo, foi cedida por um fazendeiro para seu avô e, depois de sua morte, ao pai de Mangaliso. Desde que seu pai se aposentou, em meados dos anos 80, nenhum membro da família voltou a trabalhar para os donos da terra.

Com o final do apartheid foi implementada uma série de medidas para proteger formalmente esse tipo de posse e para incluí-la no programa de reforma da terra. ${ }^{12}$ Temendo perder direitos sobre suas propriedades, muitos fazendeiros brancos pararam de utilizar a mão de obra desses moradores e começaram a forçar sua saída da área, impedindo a reparação das casas ou negando o acesso à água. O caso de Mangaliso envolvia mais diretamente seu pai, que vivia na terra desde que nasceu e passou a ser ameaçado de expulsão quando a fazenda foi vendida para um novo proprietário. Quando o pai faleceu, há cerca de uma década, a defesa da terra, das covas de seus familiares ali enterrados e das casas de seus irmãos coube ao primogênito Mangaliso. ${ }^{13}$ Desde que tomou a frente da homestead de sua família ele enfrenta todo tipo de cerceamento por parte dos proprietários. A estrada que liga sua casa à rodovia principal não recebe manutenção, suas fontes de água foram danificadas e parte de seu gado foi confiscado pelo fazendeiro porque pastava fora dos limites estabelecidos.

Mangaliso começou a se envolver em ações coletivas para tentar garantir os direitos de farm-dweller de sua família no final da década de 90 . Naquele período, ele se tornou membro do Ingogo Crisis Committee. Esse comitê foi formado com o auxílio da Association for Rural Advancement AFRA para representar os moradores daquela localidade que, no período posterior ao final do apartheid, viram seus direitos de posse da terra ameaçados e que poderiam ser incluídos como demandantes do programa de reforma da terra. Mangaliso foi escolhido pelo representante da ONG para ajudar em um levantamento sobre os casos em sua área. Para isso, receberia uma pequena remuneração.

Tendo se tornado um dos principais representantes do Comitê, foi designado para participar de outra estrutura, desta feita de âmbito provincial, que representaria todos os moradores de áreas rurais cuja posse estava sob ameaça. O Tenure Security Comittee — TSCC foi também iniciativa da AFRA e operava como uma estrutura de representação dos comitês locais de KwaZulu-Natal. O TSSC passou a ter como sede, naquele período, uma sala na casa que também servia de sede para esta ONG.

Mangaliso participou ativamente dos encontros, das marchas e das manifestações promovidas pelo TSCC em sua província no final dos anos 
90 e, em 2001, foi escolhido pelos demais membros do Comitê para ser o representante de Kwazulu-Natal em um movimento nacional que começava a se estruturar: o Landless People's Movement.

O Landless People's Movement foi formado por iniciativa da própria AFRA e de outras ONGs que desempenham papéis semelhantes nas demais províncias do país e que conceberam, ainda nos anos 90, uma entidade chamada National Land Comittee - NLC. O NLC proveu o LPM de recursos financeiros e as ONGs locais encarregaram-se de mobilizar pessoas para serem representantes na estrutura do movimento (Mngxitama 2006). Logo em seguida foi instituído um conselho nacional do movimento com representantes das diversas províncias envolvidas com o NLC. Nessa estrutura, Mangaliso, além de ser um dos membros, foi nomeado como o national organizer do movimento. Suas tarefas eram a mobilização das possíveis bases do LPM nas diversas regiões, e também a representação institucional em fóruns com o governo e na imprensa. Para esses afazeres, recebia o reembolso de seus gastos com deslocamento e com os créditos de seu telefone celular, que se tornaria uma espécie de linha de emergência para todo sem-terra de sua região denunciar abusos de fazendeiros brancos. ${ }^{14}$

Em 2004, além de ocupar a posição de national organizer do LPM, ele foi eleito para ser o chairperson (coordenador) do TSCC em Kwazulu-Natal. Ainda nesse período, Mangaliso passou a ocupar um dos assentos do board (uma espécie de conselho consultivo) da própria AFRA. No momento em que os militantes brasileiros chegaram à África do Sul, ele estava ligado a estas três organizações.

Como pudemos perceber, identificar suas ações e suas obrigações sociais apenas com a posição que ocupava no LPM não era suficiente para dar conta de sua militância. Excluindo a ONG na qual seu comprometimento era apenas consultivo, nos demais casos, ele e um grupo que não chegava a dez pessoas eram os encarregados de manter as estruturas funcionando.

Entre as pessoas que opinavam sobre a militância incoerente de Mangaliso nunca se levantava a questão de como ele fazia para manter sua família e proteger sua homestead das tentativas de expulsão orquestradas pelos donos da terra. Foi do próprio Mangaliso que ouvi esta queixa e a constatação de que, nos dez anos em que circulava com essas várias organizações, raramente ouvira referência ao fato de que ele não recebia dinheiro algum para executar as tarefas de militância, ainda que esse engajamento constante e cotidiano o impossibilitasse de ter um emprego regular. ${ }^{15}$ Corroborando seu ponto de vista, por diversas vezes fui envolvido em conversas sobre os supostos gastos desnecessários que ele tinha com o pagamento de alojamentos e transportes na cidade que sediava o TSCC e a AFRA. 
O tipo ideal de militante que todos temos em nossa cabeça não se envolve com essas tarefas ordinárias, ele parece estar acima dessas coisas, principalmente quando se trata de dinheiro. Ao acompanhar Mangaliso por um longo período, como aconteceu com os militantes do MST, os funcionários de ONGs e certos acadêmicos como eu percebemos que essas questões mundanas emergem frequentemente. Passando os dias ao lado dele, começamos a ouvir suas constantes reclamações quanto ao fato de não ter dinheiro para almoçar, de seus filhos não terem comida em casa, ou de que suas vacas (que na verdade eram de seus irmãos mais novos) estavam morrendo por falta de cuidado.

\section{Os outros movimentos de Mangaliso}

Até agora apresentei as múltiplas faces do Mangaliso militante e sem-terra - objeto central da relação que ele estabelece com os actantes que foram citados ao longo desta primeira parte. Entretanto, todos provavelmente já ouviram uma liderança falar de outras coisas que faz, fez ou viveu em seu passado. Essas outras atuações, porém, não são incorporadas à sua vida de sem-terra como provas (Boltanski 2000), mas consideradas sem valor para seu julgamento como um militante digno. Elas pertencem a outro domínio, por vezes considerado privado e, por isso, distinto e distante de sua face pública. Nas próximas páginas procurarei mostrar como a pesquisa de longa duração com este militante permitiu que fossem trazidos para a minha análise provas, objetos e socializações que não estavam prefigurados nos esquemas cognitivos que a maioria dos interlocutores do militante Mangaliso possui.

Estes novos objetos não surgiram em função de, em determinado momento da pesquisa, eu ter me afastado do tema de estudo, passando a dar atenção a novos problemas. Eles foram todos introduzidos na investigação porque apareciam com recorrência e em conjunto com eventos ligados ao LPM. Relendo anotações tomadas nesses seis anos, fui percebendo que, para convencer as pessoas a se engajarem no movimento, ele usava exemplos variados de sua experiência de vida. Muitos deles sem qualquer relação com o fato de ser um farm-dweller ameaçado de expulsão.

Em uma das visitas que fizemos em 2005 a uma township (cidade construída pelo governo do apartheid exclusivamente para abrigar de forma segregada famílias negras que trabalhavam em centros urbanos e industriais), encontramos pessoas que haviam sido expulsas de fazendas próximas. Mangaliso, disposto a convencer seus anfitriões a se engajarem 
no LPM, disse a eles que também fora um morador de township e sabia que a vida ali estava muito difícil nos últimos anos.

Cerca de um ano depois, conversávamos sobre seus primeiros momentos no LPM e ele se lembrou da trágica morte de sua esposa em um acidente envolvendo a van que ela havia pegado para visitar familiares em Johanesburgo. Mangaliso recordou que ele não a acompanhara porque teria que participar de um dos encontros de um comitê de sem-terra em uma cidade vizinha. Da história do falecimento de sua esposa, chegamos à sua vida nas townships - vida que começou cedo, pois aos dois anos de idade foi levado de Ingogo por sua avó para viver na township de Tokoza.

Tokoza ficava na periferia de Johanesburgo, cidade na qual seus avós trabalhavam como empregados domésticos, destino de muitos imigrantes de Kwazulu-Natal. Lá, Mangaliso foi educado e socializado entre outros meninos que se tornariam, como ele próprio, mão de obra para as indústrias desta grande cidade do país.

Antes de optar pelos empregos na indústria, ele foi jogador de futebol no time local - o Benfica - e teve oportunidade de atuar numa espécie de segunda divisão da principal liga do país. Naquele período, percorreu várias cidades e lembra de ter partilhado o gramado com figuras legendárias do futebol local, como Kaizer Mountaug e Jomo Sono, hoje proprietários de alguns dos maiores times da África do Sul.

Para Ingogo voltava apenas para proceder a seus rituais familiares. Mangaliso teve vários empregos e lembra com especial atenção de uma indústria de fabricação de lâmpadas na qual ocupou, por algum tempo, o cargo de coordenador, e também de ter sido entregador de produtos para lojas da Shell. Nos anos 80 ingressou como motorista no grande negócio que se expandia pelas cidades da África do Sul: as vans de transporte de passageiros moradores nas townships. No início dos anos 90 chegou a ser proprietário de alguns veículos em uma espécie de cooperativa que controlava o itinerário entre Newcastle - cidade na qual se localiza o distrito de Ingogo - e a township de Tokoza, nos arredores de Johanesburgo.

Com o dinheiro das vans, ele e sua esposa compraram um terreno próprio em Tokoza e deixaram de viver no lote dos avós de Mangaliso. Após morarem por um tempo em um barraco de paredes de zinco, construíram uma sólida casa de alvenaria de quatro cômodos.

Sua vida no mundo das vans sofreu um revés fundamental por volta de 1992. Nessa época, Tokoza transformou-se em um dos cenários dos sangrentos conflitos entre os simpatizantes do Congresso Nacional Africano - ANC e os do Inkhata Freedom Party - IFP. O Inkhata defendia a autonomia dos territórios negros ou bantustões do Estado sul-africano, corroborando os 
desejos do governo do apartheid de se livrar da administração daquelas áreas, enquanto o ANC defendia o fim dessa divisão territorial e do regime segregacionista, apoiando Nelson Mandela em sua campanha para tornarse presidente do país libertado. No conflito, Tokoza foi palco das investidas dos membros do Inkhata, que tinha sua principal base de apoio entre os Zulus, contra ativistas do ANC, Zulus ou não Zulus. Mangaliso, que era um zulu, por exemplo, apoiava o ANC e, diante das constantes ameaças de morte, abandonou sua casa e foi viver em outro local, no galpão que servia de estacionamento para as vans de sua cooperativa.

O cenário de conflitos dividiu sua família. Ele ficou no galpão dos táxis, a mulher passou a morar com a família para a qual trabalhava como empregada doméstica. Impossibilitado de seguir com o negócio dos táxis, em 1994, em pleno fim oficial do apartheid, deixou os arredores de Johanesburgo e retornou à sua cidade natal com toda a família. Eles não voltaram para a homestead de sua família na fazenda. Alugaram uma casa na township de Madadeni, na qual viviam alguns de seus parentes que foram removidos das fazendas ainda durante o apartheid. Quando perguntado por que decidiu ir para a township, ele responde que preferiu assim porque todos estavam mais acostumados à vida na cidade, principalmente seus filhos.

Vivendo na cidade, ele fazia trabalhos esporádicos, enquanto sua mulher trabalhava de doméstica. Morando na township, passou a frequentar as reuniões dos comitês que se formavam por iniciativa de ONGs, para garantir que o final do apartheid fosse marcado pela devolução das terras expropriadas da população negra.

O trágico falecimento de sua esposa o precipitaria mais ainda nesse universo. Sem a remuneração fixa que ela recebia, o pagamento do aluguel na township tornou-se inviável. Mais de quarenta anos depois de ter deixado a homestead dos Kubheka, Mangaliso voltou a viver no campo em uma casa de pau a pique, sem eletricidade ou água corrente, com seus filhos.

Mangaliso regressou a Ingogo porque lá havia uma casa pela qual ele nada pagaria para ficar. Seu retorno ao mundo rural e à condição de farm$d$ weller não estava relacionado a uma ideia de voltar para o campo e viver da agricultura ou cuidar do gado de seu pai. Mesmo sem planejar, passou a se envolver ativamente nas diversas instâncias que animam a vida associativa do vilarejo: o crisis comitte (hoje LPM/INGOGO), o comitê gestor da escola secundária (onde estudavam suas filhas), a igreja metodista e outros que não tivemos oportunidade de visitar ou tematizar. ${ }^{16}$ Embora tendo passado tanto tempo fora do lugar, ao cruzar o pouco mais de um quilômetro que demarca o vilarejo, ele saúda e é saudado por praticamente todas as pessoas que transitam entre as escolas, o abatedouro de porcos, a delegacia 
de polícia e o minimercado (pertencente a uma família de origem indiana), que conformam os limites urbanos do lugar. ${ }^{17}$ Como membro do LPM ele se tornou uma referência para todos os moradores de fazendas de brancos da região que enfrentam problemas com suas homesteads. O número de seu telefone celular e seu nome circulam pelos lugares mais remotos, toda vez que conflitos dessa ordem surgem. Em certa ocasião, abastecíamos o carro em um posto de gasolina na maior cidade da região quando o frentista perguntou a ele (vestido com a camiseta vermelha do LPM) se era mesmo o senhor Kubheka do LPM. Ao ver que estava diante da pessoa certa, o rapaz, que vivia em uma township, explicou que seu pai, morador de uma fazenda na província vizinha de Mpumalanga, estava sendo ameaçado de expulsão naquele dia. Sem titubear, Mangaliso perguntou se poderíamos cancelar nossas atividades do dia e levá-lo ao local a cerca de 100 quilômetros dali. Após alcançarmos a fazenda e desviarmos cuidadosamente do caminho que poderia nos levar a um encontro indesejado com o fazendeiro, encontramos o velho senhor que dizia ter se aposentado. Como não trabalhava mais para o fazendeiro, foi-lhe oferecido um acordo formal que previa que ele receberia um lote em um local próximo da cidade. Mangaliso instruiu-o a não aceitar o acordo, pois assim não teria qualquer garantia de ter um lugar para morar no futuro. O acordo não previa a construção de uma casa no novo espaço. Após encaminhar, por meio de seu telefone celular, o caso para um advogado que cuidava deste tipo de demandas na região, partimos de volta a Ingogo. No caminho, paramos em mais três casas de pessoas que estavam sendo ameaçadas de expulsão e cujos casos ele havia encaminhado para o Departamento de Assuntos Agrários.

No microcosmo da vida de Ingogo, ele não é apenas uma liderança do LPM. Em um domingo de fevereiro de 2008, nós o encontramos sem a tradicional camiseta vermelha do movimento. Em seu lugar, um elegante terno bege e um pedaço de feltro vermelho na lapela compunham figurino adequado para que ele participasse de uma reunião na escola e, horas depois, na sala de aula vizinha, do culto de sua igreja (cujo uniforme dos devotos é vermelho e branco). Entre os dois eventos ele ainda teve que intermediar o conflito entre uma das mães que participavam do encontro na escola e uma professora.

Naquela semana ele não havia dormido em sua casa na fazenda. Atarefado com os diversos encontros de que participara nas semanas anteriores, não tivera tempo de consertar as paredes de sua casa, que haviam ruído em razão de uma forte tempestade. Ele passara as últimas noites na casa de sua tia, que vivia mais próxima do que ele do vilarejo em uma área que lhe fora restituída, com a ajuda de Mangaliso, após o final do apartheid. 
Seria apressado dizer que a mudança para Ingogo e o envolvimento com essas instâncias locais teriam apartado Mangaliso da vida nas townships. Interessados que estávamos em tomar contato com pessoas que haviam sido expulsas de fazendas em períodos anteriores, ele rapidamente nos apontou uma série de casos que conhecia do tempo em que viveu em Madadeni. Nos dias marcados para uma dessas visitas, ele nos levou à casa de uma de suas filhas. Mangaliso nos explicou que ela morava em uma casa que na verdade era sua. A casa formada por um grande cômodo (cerca de 4 metros quadrados) fora construída há poucos anos em um terreno, nas margens da township, ocupado ilegalmente por familiares de moradores locais. Mangaliso não invadiu a área mas, ao ver que as famílias não seriam expulsas, comprou o lote de um dos invasores, onde construiu um pequeno barraco, o qual deixou sob os cuidados de sua filha quando voltou para a terra de seu falecido pai, no interior da fazenda do proprietário branco. O local foi urbanizado e casas idênticas foram construídas em um projeto habitacional público para todos que comprovaram viver nos lotes. No dia em que chegamos pela primeira vez na casa, a companhia de energia colocava os postes para iniciar a distribuição de energia. Ali viviam sua filha e quatro netos, que dependem da ajuda de Mangaliso para comprar os uniformes e o material escolar que utilizam, pois a filha solteira vive de trabalhos esporádicos no comércio da cidade.

O itinerário dos filhos de Mangaliso é também de suma importância se quisermos conhecer mais os diversos aspectos que delineiam sua vida. Seus dois filhos homens mais velhos, por exemplo, viviam em Tokoza na casa que Mangaliso havia abandonado durante os conflitos dos anos 90. Após o final das batalhas públicas entre simpatizantes do Inkhata e do ANC, ele retomou sua posse no local, deixando-o a encargo de seus primogênitos.

Assim como na casa de Madadeni, Mangaliso era também o responsável por ajudar seus filhos e netos que viviam em Tokoza em tempos de empregos escassos. Em 2008, as duas filhas que ainda viviam com ele em Ingogo terminaram os estudos e também seguiram para a township em Johanesburgo. Desde então, além de sua homestead, ele circulava com muita frequência por essas duas casas. Em cada uma delas ele precisava, ao menos, prover alimentos para seus filhos e netos.

Os filhos que mencionei até agora são aqueles que ele teve com sua esposa que faleceu no acidente de van, com quem fora casado por mais de 20 anos. Sua prole, porém, estendia-se para muito além desse casamento. ${ }^{18}$ Ao longo do tempo da pesquisa ele mencionou ter, pelo menos, outros quatro filhos, que viviam com a família das respectivas mães. Dentre estes, apenas um havia perdido contato com ele. Os demais eram visitados com 
alguma constância. Duas filhas (uma em Madadeni e outra em Tokoza) ainda recebiam alguma ajuda dele, enquanto o outro filho tinha um emprego mais estável dirigindo táxis. Este último ajudava-o com algum dinheiro nos momentos de maior necessidade.

\section{Espiral descendente}

Após quatro anos de pesquisa foi possível não apenas constatar os múltiplos envolvimentos e obrigações de Mangaliso, mas também perceber as mudanças que se deram na sua relação com esses domínios. Em 2005, ele vivia uma espécie de apogeu de sua vida de militante. Apesar de suas outras obrigações, uma comparação retrospectiva aponta aquele momento como o período em que ele despendeu mais tempo como liderança do movimento. Isto ocorreu em parte porque aquele também foi o momento de auge organizacional do LPM, com um escritório e uma secretária na casa que servia ainda para que ele pudesse pernoitar. Naqueles dias havia créditos para celulares, reembolso dos gastos com transporte e, durante a visita dos militantes do MST, um montante extra de recursos vindos da ONG inglesa War on Want (a mesma que pagava pelo aluguel da casa que servia de escritório em Johanesburgo). Com funções no LPM em Johanesburgo e em KwazuluNatal e com recursos para viajar entre os dois locais, ele podia manter-se mais próximo de suas várias casas nas townships e em Ingogo.

Já em 2006 a situação começou a se transformar. Um conflito entre as lideranças da ONG que intermediava os recursos do LPM levou ao fechamento da sede nacional em Johanesburgo. Não havia mais escritório e também não havia mais dinheiro para viagens para aquela cidade. Todos os móveis, computadores e utensílios foram levados para a sede do TSCC e da AFRA na capital de Kwazulu-Natal. Na sede da ONG ele passou a conviver mais tempo com os funcionários e, como não havia um alojamento no local para dormir, passou a fazê-lo em hospedarias (que durante o dia alugam quartos por hora). Por esta razão, ele não tinha um local para deixar seus pertences e era obrigado, todas as manhãs, a carregar sua bagagem para o escritório.

Todos os recursos, vindos de fontes internacionais, passavam pela contabilidade da ONG, que precisava autorizar seus gastos. Assim, todos os dias ele tinha que pedir dinheiro aos responsáveis. Em pouco tempo os funcionários já se mostravam visivelmente cansados dos pedidos ininterruptos e não planejados.

Em 2007, a situação do LPM piorou ainda mais. A ONG decidiu não mais permitir o uso do telefone e da internet no escritório que abrigava o TSCC 
e o LPM. Naquele ano já não havia mais recursos para hospedagem ou transporte que não fossem para eventos promovidos pela própria ONG. Mangaliso somente podia ir à sede do movimento quando um desses encontros acontecia. Como o transporte de sua casa até aquelas cidades custava quase 50 dólares americanos, ele pegava caronas e guardava o dinheiro que recebia para manter sua casa (o mesmo faziam todos os demais membros da coordenação regional do LPM). Assim, de quanto mais encontros ele participasse em nome do movimento, mais oportunidades ele teria de poupar dinheiro para distribuir entre seus filhos e netos. Sob estas condições, não demorou muito a surgir o boato entre os funcionários das ONGs, outros membros do LPM e do TSCC de que Mangaliso monopolizava a representação da organização.

Nesse período, em uma das manifestações promovidas pelo LPM e pela ONG nas ruas da capital da província, um grupo de funcionários da ONG e de ativistas do movimento foi preso. Desse grupo, apenas o caso de Mangaliso foi levado à Justiça, sob o pretexto de ter ameaçado a chefe do departamento local de reforma da terra.

Em 2008, quando ligamos para marcar um encontro, a primeira coisa que ele disse é que as coisas estavam difíceis, pois até mesmo o escritório havia sido fechado e não havia qualquer recurso para que ele se deslocasse até a cidade. Segundo Mangaliso, além da falta de recursos do movimento, havia um problema pessoal com ele: os funcionários da ONG não o queriam mais como líder do movimento, apesar de ele continuar a ser formalmente o organizer do LPM e o chairperson do TSCC. Nessa época, já se falava abertamente entre as ONGs apoiadoras do movimento que era preciso formar novos líderes e que Mangaliso não havia demonstrado capacidade de gerenciar os recursos e nem de prestar contas para os demais membros do movimento. Completando seu momento de revés, no início de 2008 ele, sem qualquer advogado ou apoio jurídico, fora condenado no processo aberto por sua prisão na manifestação do ano anterior. ${ }^{19}$ Seus três meses de cadeia foram revertidos em uma multa, porém a condenação (a terceira em sua vida e a segunda ligada ao LPM) passou a manchar sua folha criminal. Ao mesmo tempo, seu filho que dirigia táxis e o ajudava com algum dinheiro faleceu.

Apesar das crescentes dificuldades e dos boatos em torno de seu comportamento cada vez mais agressivo nos encontros de que participava, o telefone de Mangaliso não parava de tocar nos momentos em que nos encontrávamos. Eram convites para participar de seminários, de encontros com comissões do governo, com outras ONGs e, principalmente, com moradores de fazendas ameaçados de expulsão e que pediam a sua ajuda. A principal diferença é que, na maioria das vezes, ele não tinha créditos suficientes em seu telefone para completar uma ligação para essas pessoas. 


\section{De volta para a casa nova}

Não foram poucas as vozes que ouvi em 2009, em seminários e conversas com amigos acadêmicos, declarando que o LPM havia acabado. Neste mesmo ano, antes de conversar com Mangaliso, visitei um amigo ligado a uma das ONGs que haviam apoiado o LPM e ele, além de me assegurar que o movimento havia acabado, disse que Mangaliso havia virado um fazendeiro. Ironicamente, ele me comunicou que meu amigo já não poderia mais representar os sem-terra, pois havia passado para o lado dos "com terra", tendo inclusive uma casa com piscina.

Quando voltei a encontrar Mangaliso, ele estava emocionado e me contou que, depois de anos de luta, havia conseguido um pedaço de terra para morar. Mangaliso, que estava inscrito no programa de reforma agrária junto com seus irmãos como demandante da terra dos pais, foi convidado por um funcionário do Departamento de Assuntos Fundiários (local que ele frequentava semanalmente com as famílias ligadas ao LPM) a abrir mão de seu direito àquela terra (no programa de restituição) e se candidatar para receber uma área de 80 hectares (no programa de reforma da posse da terra). Esta fazenda havia sido oferecida ao governo pelo antigo dono e não estava fácil encontrar um demandante qualificado. Como já tinha experiência com os processos burocráticos que envolvem as transferências de terra pelo programa de reforma da terra, Mangaliso rapidamente conseguiu reunir toda a documentação e, com seus filhos e alguns irmãos, formou um trust (uma pequena associação) que iria receber o título da terra. Ele se tornou o representante do grupo e também o administrador da nova propriedade.

A nova casa já não era de barro, era um sobrado de alvenaria que contava com algumas benfeitorias, como estábulos, garagem, câmara fria e a controversa piscina. Como acontece em muitas propriedades vendidas ao governo, a casa foi entregue sem conexão de eletricidade, sem água corrente e com muitas de suas instalações danificadas, inclusive a piscina que, dois anos depois, continua a ser um depósito de lixo e água da chuva. ${ }^{20}$

Ao mudar para a casa, Mangaliso, não recebeu qualquer dinheiro ou crédito. Por mais de um ano a residência ficou sem luz e até os dias de hoje não há água corrente. Mesmo nesse estado, a casa de Mangaliso reúne sob seu teto uma das filhas que voltou da township, dois filhos homens que também deixaram seus empregos na periferia de Johanesburgo e três netos. Todos ali são agora sustentados pelos pequenos rendimentos advindos de um rebanho de ovelhas recebido em 2009 e de estufas de tomate construídas em 2010 com recursos do Departamento de Assuntos Fundiários. Mangaliso, que já não havia escolhido as ovelhas (teria preferido cabras, que sabia como 
lidar e cujo extensivo uso em rituais seria garantia certa de vendas), também não escolheu o tomate. Trata-se de escolhas dos técnicos do governo. Nos últimos tempos, além das atividades do LPM, ele procura mercado para ovelhas e tomates antes que as primeiras morram por falta de pasto, ou que os segundos se tornem inúteis por estarem maduros demais.

\section{Mangaliso - uma liderança em Ingogo}

Ao acompanhar os dois anos seguintes ao recebimento da terra, percebo que $o$ fato de Mangaliso ter recebido sua pequena fazenda não o tornou um farmer, como achava meu amigo da ONG. O tempo que passei com ele em 2008 e 2010 orientou-se basicamente para telefonemas e reuniões com famílias de trabalhadores rurais que estavam sendo ameaçadas por fazendeiros, com pessoas que estavam inscritas no programa de reforma da terra e com autoridades governamentais, especialmente policiais. Ele havia vendido algumas das ovelhas e comprado um carro ano 1997 que lhe dava certa mobilidade para visitar áreas mais longínquas dentro de sua cidade. ${ }^{21}$

No mesmo período, Mangaliso, junto com um reverendo branco que atendia em seus cultos a uma parte significativa dos fazendeiros da cidade em que ele vive e que representava a Agricultural District Union (ADU), formou uma espécie de aliança para evitar conflitos entre donos de terra e seus trabalhadores. Esta aliança foi interpretada como uma capitulação por certos membros das ONGs e do próprio LPM, que passaram a não mais convidá-lo para encontros e atividades promovidos por suas instituições. Alguns meses depois, ele foi entrevistado por uma revista direcionada para fazendeiros (na sua maioria brancos) e que se apresenta publicamente contra o processo de reforma agrária no país, a qual celebrava, em duas matérias, a mudança nos rumos do LPM. ${ }^{22}$ Mais tarde, em uma nova matéria, a mesma revista referia-se a Mangaliso como um ex-ativista do LPM, agora fazendeiro que promovia a paz entre sem-terra e donos de terras. As matérias ajudaram a alimentar ainda mais as controvérsias entre funcionários das ONGs e outros militantes do movimento sobre o que verdadeiramente Mangaliso estava fazendo ou representava.

O principal resultado desta aliança refletiu-se em novo tipo de telefonema que ele passou a receber: fazendeiros que pediam sua intermediação em conflitos com seus trabalhadores rurais ou com moradores de suas terras. Nestes casos, trabalhadores e fazendeiros concordavam que Mangaliso era uma chave para resolver conflitos considerados pequenos, como acesso à água, a estradas, reparação de casas e acordos sobre o número correto de animais que cada família poderia manter dentro das fazendas. Em alguns 
casos, os fazendeiros também pediam a intermediação de Mangaliso para pleitear junto ao Departamento de Terras a compra de suas áreas e seu repasse para seus trabalhadores por meio do programa de reforma da terra. ${ }^{23}$

A relação com os fazendeiros foi apenas uma das que ele estabeleceu localmente nesse período. Ele também passou a ser um mediador entre a polícia e as famílias de trabalhadores rurais, geralmente acusadas por fazendeiros de desrespeitarem regras de convivência dentro de sua propriedade. ${ }^{24}$ Durante o tempo em que estivemos em Ingogo, toda vez que havia um conflito entre fazendeiros e trabalhadores rurais, Mangaliso recebia uma ligação do chefe da delegacia de polícia para comparecer ao local. Em várias ocasiões Mangaliso nos explicou (e o próprio corregedor da polícia confirmou) que os policiais não conhecem as leis especiais (direitos civis) que regulam as relações entre trabalhadores rurais e fazendeiros e que apenas aplicam os preceitos do direito criminal para o qual são treinados.

Todos esses envolvimentos tornaram insustentável a relação de Mangaliso com a ONG que o havia formado como liderança e de cujo conselho era membro efetivo. Em uma nova matéria da Farmers Weekly, no final de 2009, Mangaliso tornou pública uma de suas maiores queixas contra o papel das ONGs: o fato de o dinheiro recebido para apoiar o movimento estar sendo usado para organizar manifestações que perturbavam as negociações com fazendeiros e para incentivar outros membros do LPM a desafiarem as ações do próprio Mangaliso. Segundo a revista, ele teria dito que as ONGs agiam desta forma porque estariam mais interessadas em criar conflitos do que em resolvê-los pois, se isso acontecesse, elas acabariam ao longo do tempo. Em uma das edições seguintes da revista foi publicada uma carta enviada por outros militantes do LPM que defendiam a ONG e acusavam Mangaliso de não ser representante legítimo do movimento.

Logo após a reportagem, ele recebeu em sua nova casa uma carta comunicando que o conselho da ONG havia decidido por sua expulsão. $\mathrm{Na}$ carta, a reportagem era mencionada e foi estabelecido um curto prazo para que ele se defendesse das acusações. Além disso, como ele estava em atraso com as taxas que cada membro da organização deve pagar anualmente (embora nunca houvesse pago tal taxa e tampouco sido cobrado por isso antes de ter criticado a atuação da ONG), sua expulsão aconteceria a despeito de qualquer justificativa que apresentasse a respeito da acusação.

A ruptura com a AFRA não o afastou do LPM. Durante o ano de 2010, nós o acompanhamos, assim como outros membros do movimento, em negociações com a mesma ONG e outras duas para arrecadar fundos para um encontro provincial do movimento. Este encontro ocorreu no segundo semestre de 2010 e nele Mangaliso foi eleito provincial organizer. 
Se comparadas a 2005, as atividades de Mangaliso estão agora muito mais restritas à sua própria cidade. É lá que ele tem atuado intensamente, seja como LPM, seja como parte dos grupos de intermediação de conflito, como membro da igreja e como fazendeiro/sem-terra. Sem as atividades promovidas por ONGs, ele dedica a maior parte de seu tempo - e de seus créditos do telefone celular - a intermediar contendas locais. Isto não impede, entretanto, que ele continue a ser convocado para eventos internacionais. A última vez em que nós nos encontramos foi no aeroporto de Johanesburgo, antes de ele embarcar para uma viagem de uma semana para o Zimbabwe, onde representaria a La Via Campesina Africa como membro do LPM.

\section{Legítimos, ilegítimos e plurais}

O caso de Mangaliso, quando colocado ao lado de outras pesquisas que havia realizado no Brasil com militantes do MST, revela-se uma ferramenta comparativa fundamental. Seus múltiplos engajamentos - que somente puderam ser percebidos em função da longa duração da pesquisa — obrigavam a uma ampliação das classificações originárias da própria pesquisa. Até onde poderíamos associar sua atuação no LPM à sua vida rural ou de sem-terra?

Nos últimos anos, a teoria sociológica tem avançado no debate sobre as formas de tratamento da diversidade de experiências na vida dos sujeitos que encontramos em nossas pesquisas. A preocupação com este tema advém dos limites e das implicações políticas que as generalizações, tão caras aos nossos tipos e às nossas trajetórias ideais de militantes, vendem como um retrato verdadeiro de nossos objetos. Autores como Luc Boltanski (2000) e Boltanski e Theventot (1991) e Bernard Lahire (1998, 2004 e 2006), por caminhos diferentes, tentam desafiar certo tipo de sociologia tradicional. Mesmo que consideremos que um sujeito tenha uma trajetória irregular, não podemos nos furtar de acompanhar essas linhas tangenciais, esses altos e baixos, e decidir simplesmente por reduzir os homens e as mulheres de nossos estudos aos limites de um olhar teórico que já havia de antemão elegido sua definição enquanto objeto. Os autores apontam, sobretudo, para os limites dos estudos que constroem os camponeses, os miseráveis, os trabalhadores e, é claro, os sem-terra como categorias-força que subsumem todos os indivíduos entrevistados ou etnografados em nossas pesquisas.

Para Lahire (1998 e 2004), os estudos tradicionais sobre a relação entre indivíduos e pertencimentos sociais a certos grupos admitiam facilmente a ideia de que os sujeitos que formam um movimento, por exemplo, podiam ser diferentes entre si. No entanto, foi sempre um tabu entre os cientistas sociais 
pensar no que ele define como as "variações intraindividuais" (Lahire 2006), ou seja, diferenças de atitudes, gostos e opiniões dissonantes em um mesmo caso. Embora este autor não faça tal comparação, é possível perceber que diante das incoerências ou das mudanças de atitude de nossos sujeitos/objetos somos tentados a usar expressões derrogatórias como "fragmentação", por exemplo.

Outra saída comum que encontramos para descrever situações como essa é a ideia da "conversão", tão cara ao legado bourdiano. Nessa chave, há espaço para mudanças nas "trajetórias" individuais sem que isso seja tratado como um exemplo de desagregação social dos sujeitos. No entanto, a apresentação da mudança se dá por meio da construção de pertencimentos sólidos, como família ou religião, que se "convertem" em outros também rígidos, como a atuação em movimento social. Nesses casos, tendemos apenas a privilegiar a mudança de um estado a outro, de um tempo a outro, mas continuamos com a dificuldade de tratar de pertencimentos ou socializações simultâneos, nem sempre convergentes ao olhar do investigador, especialmente quando se localizam fora de nosso objeto.

No caso de Mangaliso, este tipo de abordagem teria limites claros, pois seria difícil afirmar que ele converteu seu passado - capital, como a tradição bourdiana definiria - urbano para transformar-se um uma liderança de sem-terra. Rural e urbano, sem-terra e morador de township, religião, política e família operam simultaneamente em sua vida.

Limites da mesma ordem podem ser atribuídos também aos estudos de Norbert Elias sobre indivíduos e figurações sociais. Quando vemos o complexo Mozart, de Elias (1995) oscilar entre o refinamento musical e a escatologia da vida subalterna na corte, observamos uma vida dividida entre dois polos. A figuração um tanto atrasada da corte austríaca e a moderna do mercado musical ascendente em outras cidades da Europa são, no Mozart de Elias, um paradoxo instransponível - intransponível porque aos olhos de quem o julgava cotidianamente, seus pares na família ou círculos cortesãos de Paris ou Berlim, ele, em momentos-chave, mostrava-se incompatível com as expectativas da posição. A descrição acurada que Elias faz desse indivíduo, no entanto, prende-o entre essas únicas possibilidades ou figurações que moldariam sua personalidade. O destino fatal do personagem ajuda a compor o quadro do indivíduo que sucumbe porque não está em harmonia com o que se espera dele. O Mozart de Elias torna-se eficaz sociologicamente não em razão de sua complexidade, mas pelo fato de ele não conseguir ser simples o suficiente para se encaixar nos modelos de sociedade de corte que lhe são apresentados. Falta no músico a pureza ou a coerência que tanto nos agrada quando nos valemos dos tipos ideais - estratégia amplamente criticada por Elias (1982). Ao final deste livro e de outros, como Sociedade de corte, ou os 
Alemães, temos dramas individuais que ajudam a reforçar um modelo, sempre cambiante, mas um modelo de figuração que prende os sujeitos. Ficamos a procurar as coerências e as incoerências em relação a essas construções. O caso de Mangaliso nos ajuda a ver a força desses modelos por meio das sanções e das reprimendas que ele sofre de todos os lados.

O problema da análise de Elias, visto a partir desta ótica, é que ela dá margem para se pensar que a incoerência dos sujeitos é socialmente fatal. Tomando o caso exemplar do indivíduo que fracassa, ele se abstém, no entanto, de nos fornecer qualquer pista para afirmar que os que "deram certo" eram menos incoerentes que Mozart. Não por acaso, assim como Bourdieu, Elias trabalha com a ideia de habitus, que caminha justamente para apontar a coerência entre a posição atual dos sujeitos e o legado que receberiam de sua figuração. ${ }^{25}$ O ponto que pode ser levantado após esse longo tempo com Mangaliso é até onde podemos afirmar qual a verdadeira figuração de nossos personagens quando, na maioria dos casos, nosso contato com eles se define apenas por nosso objeto de estudo? O papel deste caso, quando comparado com os anteriores experienciados junto a militantes do MST no Brasil, é demonstrar que podemos escrever sobre indivíduos sem a perigosa necessidade de demarcar o que eles são ou foram ou de associá-los facilmente a uma figuração.

Uma saída alternativa e mais frutífera para captar metodologicamente essas variações intraindividuais é a sociologia cognitiva de Boltanski (2000). Segundo este autor, os trânsitos entre pertencimentos sociais distintos podem ser traçados quando deixamos de construir nossos objetos de uma posição exterior ao mundo social que estudamos. Sua reivindicação de uma reconstrução cognitiva dos modos como os indivíduos atuam toma as ações dos sujeitos como o ponto de partida para a compreensão das várias legitimidades que perpassam seu cotidiano. O centro da análise são ações que legitimam e, por isso, justificam a presença de um sujeito em certos espaços sociais.

Ao olharmos para o modo como as pessoas que se relacionavam com Mangaliso através do LPM julgavam suas ações, poderemos perceber claramente os limites, neste caso específico, do que se considera legítimo para um militante. Ele é legítimo quando é um farm-dweller e quando se dedica ininterruptamente ao movimento, quando não critica publicamente as ONGs. Porém, quando ele não apresenta as provas necessárias ou quando suas provas de legitimidade do movimento misturam-se com outras como a família - o que inevitavelmente acontece na situação atual do LPM — e a nova fazenda, ele é rapidamente condenado.

Para os fins deste texto, seus conflitos de legitimidade servem para pensar nas armadilhas e nos limites do que é possível escrever quando estamos nos referindo aos ativistas políticos. Como - em grande parte dos casos 
de nossas pesquisas - não temos tempo nem habilidade para incorporar as variações intraindividuais de nossos sujeitos/objetos, tendemos a tornar público, científico e verdadeiro um tipo de experiência que requer certas provas. Como almejamos tornar isso público, inevitavelmente colaboramos para que algumas provas sejam aceitas para medir o grau de engajamento dessas pessoas. O desafio de um caso como este está em trazer as provas dissonantes para o que tornamos público, sem deslegitimar os militantes.

\section{Conclusão}

Como vimos com o caso de Mangaliso, as categorias e as generalizações que confortam e assombram os cientistas sociais que estudam movimentos sociais estão também presentes nas atitudes dos demais sujeitos que lidam com esse universo. Na verdade, elas estão presentes na vida dos próprios sujeitos/objetos e tendem a guiar seus sentimentos de satisfação ou insatisfação com suas condutas. Quando desenhamos nossas pesquisas, quando as ONGs fazem seus projetos ou quando partimos para uma visita aos nossos equivalentes de outros continentes, esperamos por lá encontrar sujeitos que correspondam minimamente aos modelos.

O caso da militância política torna-se especial neste contexto porque nela estão contidas aspirações de mudança social que se realizariam por meio desses sujeitos. Cada vez que Mangaliso se mostrava interessado em dinheiro, cada vez que se atrasava para uma reunião porque tinha que visitar os seus filhos, ele abalava a própria crença nos sem-terra como uma categoria. Para felicidade nossa, pesquisadores, esses momentos podem ser apagados de nossos textos ou evitados quando, por imposição de prazos, dispomos de pouco tempo para vivenciá-los. No caso das ONGs e de outros militantes que não podem evitar esse contato, é possível separar o universo da ação política das outras obrigações sociais de nossos heróis e não perguntar, por exemplo, como eles fazem para sobreviver se estão todo o tempo no movimento. Outra opção é romper relações com certas lideranças tidas como incoerentes.

Como a tendência é trabalharmos com tipos-ideais ou figuração (em perspectivas mais realistas), é fácil deixar de lado o fato de que um sujeito como Mangaliso tem um envolvimento razoavelmente recente com a terra ou com os movimentos sociais. Em mais de cinco décadas de vida ele já foi muita coisa, e continua a ser várias delas. Seu envolvimento com as vans e com a vida na township continua a existir a despeito de seu intenso envolvimento com o LPM. Sua casa em Tokoza ainda está de pé, assim como as de seus irmãos que lá vivem. O mesmo ocorre com seu passado de estrela do futebol, 
pois para ele esta é a razão de ter tido tantos relacionamentos amorosos que hoje lhe rendem obrigações com filhos espalhados por várias cidades.

São essas heranças do passado, que não foram "reconvertidas" nem integradas coerentemente à sua vida de militância, que continuam a assombrar suas relações com os que estão à volta do movimento e, principalmente, a desafiar as ciências sociais na direção de uma nova perspectiva plural sobre a atuação política individual e coletiva.

Recebido em 19 de abril de 2011

Aprovado em 20 de agosto de 2011

Marcelo C. Rosa é professor do Departamento de Sociologia da UnB. E-mail:

$<$ marcelocr@uol.com.br>

\section{Notas}

* Agradeço ao próprio Mangaliso Kubheka por ter concordado com os termos deste texto. As informações que ajudam a compor os múltiplos engajamentos sociais de Mangaliso apresentados neste artigo são o resultado de um processo coletivo de pesquisa compartilhado com as colegas Antonádia Borges, Joyce Gotlib e Aina Guimarães. Este artigo origina-se de trabalho de pesquisa apoiado pelo edital IBSA/ IUPERJ/Fundação Ford 2006 e pelo CNPq.

${ }^{1}$ Uso aqui o termo "reforma da terra" para designar o programa de "Land Reform" sul-africano e para marcar sua diferença com o termo "reforma agrária", que tem sido usado no Brasil nas reivindicações de sem-terras.

${ }^{2}$ O trabalho de Baletti, Johnson e Wolford (2008:301) é exemplar sobre este tipo de uso no qual o indivíduo é reduzido ao movimento e vice-versa. Para justificar o emprego de uma entrevista com o próprio Mangaliso para descrever os dilemas do LPM, as autoras afirmam que suas respostas na entrevista representam as "mentalities of key figures" e a trajetória do movimento.

${ }^{3}$ A igreja na qual Mangaliso é um preacher se chama The Methodist Church of South Africa. Quando ele usa a expressão our culture (nossa cultura), na maioria dos casos se refere às práticas sociais dos zulus ou dos suazi (grupos étnicos com os quais afirma compartilhar laços). 
${ }^{4}$ A clássica coletânea organizada por Casagrande (1960), sobre os "informantes" que contribuíram para a construção de algumas das mais importantes etnografias da primeira metade século XX, é um exemplo da apresentação de personagens por meio dos laços exemplares que nutrem com sua cultura e com suas posições sociais.

${ }^{5} \mathrm{Na}$ tentativa de comparar o que seria o sucesso do MST com o fracasso do LPM, Baletti, Johnson e Wolford (2008) utilizam um manuscrito meu para demonstrar que as lideranças do movimento sul-africano não teriam o mesmo nível de dedicação ao movimento que os militantes do MST. Tanto em meu texto (datado de 2007 e resultante dos dois primeiros anos da pesquisa, quando estava ainda muito influenciado pelos modelos de militância do MST) quanto no das pesquisadoras acima referidas, há um preocupante juízo de valor sobre o fazer político. Nos dois casos avalia-se a fórmula do MST como a maneira correta - para todos os movimentos - de formar lideranças. Como eu mesmo não conhecia suficientemente o LPM e a vida social de seus líderes, acabei por transmitir a outros colegas uma visão parcial e simplista que impunha o modelo brasileiro como legítimo.

${ }^{6}$ Esta perspectiva deve hoje ser relativizada na medida em que boa parte de minhas próprias análises sobre lideranças locais do MST estavam limitadas por um convívio e por técnicas de pesquisa que pouco permitiam a emergência de controvérsias que envolvessem a condição de militantes e outros aspectos da vida coletiva. Em geral, trabalhei (como em Rosa 2011) apenas com entrevistas e etnografia de momentos internos ao movimento.

${ }^{7}$ Uma inspiração fundamental para pensar os limites da vida em movimento para a compreensão da vida social de seus militantes pode ser encontrada na crítica que Silva (2008) faz da literatura sociológica que reduz a vida dos "adolescentes em conflito com a lei" aos termos que circunscrevem e justificam seu envolvimento com atividades ilegais.

${ }^{8}$ É preciso lembrar que naquela época o MST contava com milhares de militantes profissionais em todo o país, enquanto o LPM não contava com mais de 20 pessoas que deveriam organizar o movimento, mobilizar os sem-terra, angariar fundos e negociar com o governo.

${ }^{9}$ Por relações estreitas, refiro-me especialmente à sua participação em reuniões organizadas pelo Departamento de Assuntos Fundiários (DLA). Sobre as formas de atuação deste órgão e de seus agentes, ver o trabalho de Gotlib (2010).

${ }^{10}$ As críticas a Mangaliso sintetizam as várias ressalvas que ouvi para o fato de o LPM ter sido criado e, em certa medida, controlado por um grupo de ONGs que atuavam em áreas rurais do país. Para esses críticos, o LPM não teria nascido de uma mobilização espontânea dos sem-terra locais, e isto macularia sua história desde o início. Para mais informações, ver os trabalhos de Greenberg (2006) e Sihlongonyane (2008).

${ }^{11}$ Seria possível fazer uma aproximação entre o farm-dweller sul-africano e o morador das fazendas de cana de açúcar no nordeste brasileiro descrito por Palmeira (1978). Prefiro, no entanto, em nome das diversas peculiaridades que envolvem cada caso, manter a grafia em inglês, largamente utilizada naquele país. 
Nas diversas entrevistas que fizemos com farm-dwellers da região de KwazuluNatal, encontramos casos de pessoas que moravam na fazenda sem pagar taxas e sem trabalhar para o fazendeiro, e outros que trabalhavam, recebiam salários e tinham descontados de seus vencimentos taxas pela posse de gado e pelo uso das casas (em geral, construídas por eles mesmos). Entre um caso e outro há um aspecto de práticas diversas que são englobadas pelo termo legal farm-dweller. Para o caso das relações que são reguladas por contrato de trabalho, usa-se também a categoria labour tenant.

${ }^{12}$ Em 1997 foi implementado o ESTA - Extension of Security Tenure Act - que visa regular e garantir a posse da terra para os farm- $d$ wellers sul-africanos. No ESTA há uma bula que busca regular as obrigações de trabalhadores rurais e fazendeiros nesse tipo de relação. O ESTA usa o termo occupier para definir aqueles que são passíveis de serem protegidos por seus artigos.

${ }^{13} \mathrm{O}$ trabalho de Borges (2011) etnografa o envolvimento dos militantes do LPM e do próprio Mangaliso com os burial sites de seus familiares e companheiros de movimento, e a importância destes para as lutas por terra na África do Sul contemporânea. James (2007) analisa a importância dos burial sites nas reivindicações por terra na província de Mpumalanga.

${ }^{14} \mathrm{Na}$ África do Sul, as operadoras de telefone celular oferecem um serviço gratuito no qual é possível enviar para outra pessoa uma mensagem dizendo "call me back" ou "me ligue de volta". Mangaliso recebe dezenas de mensagem dessas por semana de moradores de áreas rurais que, sem dinheiro, pedem seu auxílio na intermediação de conflitos com fazendeiros.

${ }^{15}$ No caso do MST, os militantes que se dedicam em tempo integral ao movimento recebem uma pequena ajuda de custo em dinheiro para suas despesas.

${ }^{16}$ Essa igreja, assim como todas as demais que existem na localidade, não possui uma sede. Seus cultos são realizados nas salas de aula da escola aos domingos. Até o momento da feitura deste artigo não realizei qualquer pesquisa específica sobre a atuação religiosa de Mangaliso.

${ }^{17}$ É preciso ressaltar que essas saudações são geralmente dirigidas ao seu praise name (izithakazelo), ou seja, ao nome de sua linhagem familiar. Entre os Zulus, além de denotar respeito, o uso desta expressão mostra um conhecimento íntimo sobre a origem da pessoa que se cumprimenta.

${ }^{18} \mathrm{Na}$ África do Sul, a poligamia é permitida e é muito comum em áreas rurais. Mangaliso, entretanto, nunca chegou a oficializar sua relação com as mães destes filhos por diversos motivos.

${ }^{19}$ Acompanhei Mangaliso em pelo menos duas audiências sobre este caso. Em ambas, por não ter advogado, o caso foi adiado, tendo ele que arcar com todas as despesas do próprio julgamento. 
${ }^{20}$ Nem Mangaliso nem seus netos e filhos sabem nadar.

${ }^{21}$ Em janeiro de 2011, Mangaliso nos contou que o carro estava parado na garagem havia cinco meses, pois não tinha dinheiro para comprar peças de reposição.

${ }^{22}$ Farmers Weekly, edições de 19/09/2008 e 28/10/2008.

${ }^{23}$ Para compreender este tipo de pedido é importante notar que o programa de reforma da terra na África do Sul adotou o modelo "willing buyer/willing seller" do Banco Mundial. Conhecido no Brasil por "reforma agrária de mercado", este modelo não incluiu entre seus expedientes a desapropriação de terras, e sim sua compra.

${ }^{24}$ Sobre o papel controverso da polícia nas denúncias oferecidas por fazendeiros e por trabalhadores rurais, ver o trabalho de Paula Monteiro (2010).

${ }^{25}$ Afirmar que ambos utilizam a ideia de habitus não significa dizer que o conceito tenha o mesmo sentido e o mesmo estatuto na obra desses dois autores.

\section{Referências bibliográficas}

AUYERO, Javier. 2004. Vidas beligerantes. Dos mujeres argentinas, dos protestas y la búsqueda de reconocimiento. Buenos Aires: Universidad Nacional de Quilmes Editorial.

BALETTI, Brenda; JOHNSON, Tamara \& WOLFORD, Wendy. 2008. "'Late mobilization': transnational peasant networks and grassroots organizing in Brazil and South Africa". Journal of Agrarian Change, 8(2-3):290314.

BOLTANSKI, Luc. 2000. El amor y la justicia como competências: tres ensayos de sociologia da ação. Buenos Aires: Amorrortu Editores. . \& THEVENTOT, Laurent. 1991. De la justificacion. Paris: Galimard.

BORGES, Antonádia. 2011. "Sem sombra para descansar: etnografia de funerais na África do Sul contemporânea". Anuário Antropológico (no prelo).
BOURDIEU, Pierre. 1996. "A ilusão biográfica". In: Marieta de Moraes Ferreira \& Janaína Amado (orgs.), Usos e abusos da história oral. Rio de Janeiro: Fundação Getúlio Vargas. pp. 183-191.

CASAGRANDE, Joseph B. (org). 1960. In the company of man: twenty portraits of anthropological informants. New York: Haper Torchbooks

ELIAS, Norbert. 1982. La sociedad cortesana. Mexico: Fondo de Cultura Económica. . 1994. A sociedade dos indivíduos. Rio de Janeiro: Jorge Zahar. . 1995. Mozart. Sociologia de um gênio. Rio de Janeiro: Jorge Zahar Editor.

FILlieUle, Olivier. 2001. "Propositions pour une analyse processuelle de l'engagement individuel: post scriptum". Revue Française de Science Politique, 51(1-2):199-215.

GAXIE, Daniel. 2002. "Appréhender le politique à l'aube des expériences 
sociales". Revue Française de Science Politique, 52(2-3):145-178.

.\&OFFERLÉ, Michel. 1985. "Les militants syndicaux et associatifs au pouvoir? Capital social collectif et carrière politique". In: P. Birnbaum (dir.), Les élites socialistes au pouvoir. Paris: PUF. pp. 105-138.

GOTLIB, Joyce. 2010. Getting land back to the people: a interdependência entre governo e ongs na produção de beneficiários por terra da província de KwaZulu-Natal, África do Sul. Dissertação de Mestrado, Programa de PósGraduação em Sociologia e Direito, Universidade Federal Fluminense.

GREENBERG, Stephen. 2006. "The Landless Peoples Movement and the failure of Post-Apartheid Land Reform". In: R. Ballard; A. Habib e I. Valodia (orgs.), Voices of protest: social movements in post-apartheid South Africa. Durban: UKZN Press.

LAHIRE, Bernard. 1998. Homem plural: os determinantes da ação. Petrópolis: Vozes.

.2004. Retratos sociológicos. Porto Alegre: Artmed.

.2006. A cultura dos indivíduos. Porto Alegre: Artmed.

LATOUR, Bruno. 2005. Reassembling the social: an introduction to actor-network-theory. Oxford: Oxford University Press.

JAMES, Deborah. 2007. Gaining ground: "rights" and "property" in South African Land reform. Londres: Routledge-Cavendish.

MNGXITAMA, Andile. 2006. "The taming of land resistance: lessons from the National Land C"mmittee". Journal of Asian and African Studies, 41(12):39-69.

MONTEIRO, Paula. 2010. Desafiando o direito de propriedade: O embate entre diferentes concepções de direito a terra no contexto de reforma agrária sul-africana. Monografia de Graduação, UFF, Niterói.

OLIVEIRA, Wilson José Ferreira de. 2008. "Gênese e redefinições do militantismo ambientalista no Brasil". Dados, 51(3):751-777.

PALMEIRA, Moacir. 1978. "Casa e trabalho: notas sobre as relações sociais na plantation tradicional". Actes du XLII Congrès des Américanistes. Paris: Société des Américanistes/Musée de l'Homme. pp. 305-315.

ROSA, Marcelo C. 2001. “Espetáculo e cotidiano, pequenas vozes na luta do MST". Cultura Vozes, 95(3):83-93. . 2009. "Biografias e movimentos de luta por terra em Pernambuco". Tempo Social, 21(1):157-180.

2011. O engenho dos movimentos sociais: reforma agrária e significação social na zona canavieira de Pernambuco. Rio de Janeiro: Garamond.

SEIDL, Ernesto. 2009. "Disposições a militar e lógica de investimentos militantes". Pro-Posições, 20(2):21-39.

SIGAUD, Lygia. 2005. "As condições de possibilidade das ocupações de terra". Tempo Social, 17(1):255-280.

SIHLONGONYANE, Mfaniseni Fana. 2008. "La ocupación de tierras en Sudáfrica". In: Sam Moyo \& Yeros Paris (orgs.), Recuperando la tierra. El resurgimiento de movimientos rurales en África, Asia y América Latina. Buenos Aires: CLACSO. pp. 157-180.

SILVA, Marília Márcia C. da. 2008. Meninas à prova: um estudo sobre as justificações de adolescentes em conflito com a lei. Dissertação de Mestrado em Sociologia e Direito, Niterói, PPGSD/UFF.

STENGERS, Isabelle. 2002. "Un engagement pour le possible". Cosmopolitiques, 1: 27-36. 


\section{Resumo}

Este artigo procura analisar as histórias que se cruzam com o engajamento político de um militante do Landless Peoples Movement, na África do Sul contemporânea. Por meio do estudo da relação desta liderança com o movimento, com sua bandeira de luta e com outras dimensões de sua vida coletiva, procurarei discutir alguns dos desafios que as ciências sociais enfrentam quando buscam associar indivíduos e processos sociais. Com esta análise pretendo chamar a atenção para os limites dos estudos tradicionais sobre militantes políticos e para a necessidade de incorporação de perspectivas plurais no que tange à análise das ações coletivas por parte das ciências sociais.

Palavras-chave Biografias, Movimentos sociais, Militantes, África do Sul, Semterra.

\section{Abstract}

This article analyzes the series of histories that intersect with the political engagement of an activist from the Landless Peoples Movement in contemporary South Africa. Based on a study of the relation between this leader and the movement, campaign issues and other dimensions of collective life, I discuss some of the challenges facing the social sciences when they seek to associate individuals with social processes. Through this analysis I look to call attention to the limits of traditional studies of political activists and the need for the the social sciences to incorporate plural perspectives into any analysis of collective action.

Key words Biographies, Social Movements, Activists, South Africa, Landless. 